
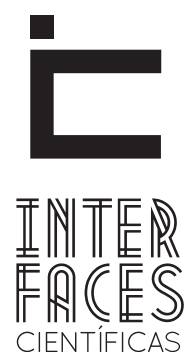

EDUCAÇÃO

ISSN IMPRESSO 2316-333X

ISSN ELETRÔNICO 2316-3828

\title{
OS FUNDAMENTOS DE UMA PEDAGOGIA SOCIAL CRÍTICA
}

Sanna Ryynänen ${ }^{1}$

\section{PARTE 1}

\section{RESUMO}

A construção e o desenvolvimento da pedagogia social tem sido atribuída a três perspectivas meta-teóricas: positivista ou técnica, hermenêutica ou interpretativa e critica ou emancipadora, cada uma com a sua própria história de reflexão teórica e, como tal, as suas próprias características enquanto uma prática educacional e social. No artigo, procuramos esclarecer os fundamentos de pedagogia social crítica, analisando as suas variadas raízes, com o objetivo de entender melhor o seu significado no Século XXI. Na discussão, abordamos o reformismo social do final do Século XIX; a teoria crítica da Escola de Frankfurt; a virada crítica da pedagogia social na Alemanha depois da Segunda Guerra Mundial; e a pedagogia da libertação dos anos
1960 na América Latina. Entendemos esses assuntos como componente que têm contribuído na construção da abordagem que denominamos de pedagogia social critica, e concluímos que a sua essência é esta: a pedagogia social crítica carrega fundamentos políticos e ideológicos que the orienta para a transformação social rumo a uma sociedade mais justa e mais igualitária, com os processos educacionais dialógicos e anti-hierárquicos que se baseiam nos ideais do encontro entre os sujeitos iguais e da reflexão crítica.

\section{PALAVRAS-CHAVE}

Pedagogia Social. Pedagogia Social Crítica. Educação. 


\section{ABSTRACT}

The construction and development of social pedagogy have been assigned to three meta-theoretical perspectives: positivist or technical, hermeneutic or interpretative, and critical or emancipatory, each with a specific history of theoretical reflection and, as such, with specific characteristics as educational and social practices. In this article, we aim to specify the foundations of critical social pedagogy by analysing its different roots, with an objective to better understand critical social pedagogy in the 21st century. We address the Social Reformism of the end of the 19th century, the Critical Theory of the Frankfurt School; the critical turn of the German social pedagogy after the Second World War, and the Latin American libe- rating pedagogy of the 1960s. We understand these issues as components that have contributed in the construction of the approach that we call social critical pedagogy, and conclude that the essence is this: social pedagogy critical loads political and ideological foundations that guides you to the social transformation towards a more just society and more egalitarian, with dialogic educational and anti-hierarchical which are based on the ideals of the encounter between equal subjects and critical reflection.

\section{KEYWORDS}

Social Pedagogy. Critical Social Pedagogy. Education.

\section{RESUMEN}

La construcción y el desarrollo de la pedagogía social se ha atribuido a tres puntos de vista meta-teóricos: positivistas o técnicos, hermenéuticos o interpretativos y críticos o de emancipación, cada uno con su propia historia de reflexión teórica y, como tal, a con sus propias características como una práctica educativa y social. En el artículo, se clarifican los fundamentos de la pedagogía social crítica analizando sus diversas raíces con el fin de comprender mejor su importancia en el Siglo XXI. En la discusión, se aborda el reformismo social de los finales del Siglo XIX; la teoría crítica de la Escuela de Frankfurt; el cambio crítico de la pedagogía social en Alemania después de la Segunda Guerra Mundial; y la pedagogía de la liberación de la década de 1960 en América Latina. Entendemos estos temas como componentes que han contribuido en la construcción del enfoque que llamamos de pedagogía social critica, y concluimos que su esencia es la siguiente: la pedagogía social crítica carga fundaciones políticas e ideológicas que le guían a la transformación social hacia una sociedad más justa y más igualitaria, con procesos educativos anti-jerárquicos y dialógicos que se basan en los ideales de encuentro entre las personas iguales y en la reflexión crítica.

\section{PALABRAS-CLAVE}

Pedagogía Social. Pedagogía social crítica. Educación. 


\section{INTRODUCÇÃO}

As tentativas de definir a "essência" da pedagogia social, ou um "foco" que dá a esta o seu caráter especifico, são inúmeras. A pedagogia social tem sido caracterizada, por exemplo, como uma abordagem que se dedica ao desenvolvimento das competências sociais e aos modos de convivência, que reconhece a necessidade de trabalhar simultaneamente com as pessoas e as comunidades, que dá suporte à participação individual e coletiva, que reconhece que os processos educacionais relacionam-se, essencialmente, com a sociedade e que entende o termo educação, tal como o social, de maneira ampla (RYYNÄNEN, 2012).

Porém, as definições gerais do caráter básico da pedagogia social ficam vazias sem um aprofundamento ontológico, epistemológico e axiológico, ou seja, sem refletir e especificar os seus fundamentos histórico-teóricos e filosófico-ideológicos. Isso implica na necessidade de aprofundar a noção das orientações meta-teóricas ou paradigmas da pedagogia social (que aqui são usados como sinônimos) que convivem no seu campo teórico e trazem consigo uma pluralidade das perspectivas - ao ponto de, às vezes, parecerem até contraditórias.

Sáez (1997) atribui a construção e o desenvolvimento da pedagogia social a três perspectivas meta-teóricas: positivista ou técnica, hermenêutica ou interpretativa e critica ou emancipadora, cada uma com a sua própria história da reflexão teórica e, como tal, com suas próprias características enquanto uma prática educacional e social. Cada uma tem a sua visão distinta sobre o objeto da pedagogia social, como também de seus métodos e formas de produção cientifica.

Com uma distinção entre o "universo frio" e o "universo quente" da animação sociocultural, o francês Jean-Claude Gillet (1995 apud KURKI, 2006) acaba ilustrando - de maneira até simplista, mas, como tal, também clarificante - os pressupostos principais quase opostos das perspectivas meta-teóricas técnicas e críticas.

Para Gillet (1995 apud KURKI, 2006) o universo frio caracteriza-se pela orientação vertical do trabalho, de cima para baixo, e pela "consumpção" dos métodos e das técnicas. 0 trabalho socioeducativo, assim orientado, procura manter o status quo com tentativas de influenciar as consequências da desigualdade social. O foco principal é dar suporte ao ajuste da situação atual. Definido assim, o universo frio é análogo ao paradigma positivista ou técnico da pedagogia social (SAÉZ, 1997).

O universo quente definido por Gillet (1995 apud KURKI, 2006) coincide com o paradigma crítico da pedagogia social. A pedagogia social crítica surge como uma reação contra as estruturas opressivas e o trabalho educativo é visto como uma resistência social em vez de um modo de (meramente) ajustarse à situação atual. 0 objetivo é alcançar as condições que possibilitam igualdade e justiça a todas as pessoas (RYYNÄNEN, 2012).

No artigo, procuramos esclarecer os fundamentos da pedagogia social crítica, analisando as suas variadas raízes, com o objetivo de entender melhor o seu no Século XXI. Na discussão, abordamos o reformismo social do final do Século XIX; a teoria crítica da Escola de Frankfurt; a virada crítica da pedagogia social na Alemanha depois da Segunda Guerra Mundial; e a pedagogia da libertação dos anos 1960 na América Latina. Entendemos esses assuntos como componentes que têm contribuído na construção da abordagem que denominamos agora, no Século XXI, de pedagogia social crítica. Além disso, situamos a pedagogia social crítica como uma das vertentes do pensamento educacional crítico, com filiações em abordagens tais como a animação sociocultural e a pedagogia crítica. 
O objetivo do texto é ultrapassar a mera discussão teórica e meta-teórica e abordar questões tais como: Qual é o papel da pedagogia social na sociedade contemporânea? O que ele deveria ser? Como esse papel é e poderia ser exercido?

\section{JANE ADDAMS E O REFORMISMO SOCIAL}

No final do Século XIX, a estadunidense Jane Addams (1860-1935) viajou para a Europa com a intenção de conhecer melhor a realidade europeia. Ao ver a pobreza das classes trabalhadoras nas grandes metrópoles, tais como Londres e Berlim, Addams, filha de uma família de classe nobre, desesperou-se, mas logo o desespero se transformou em uma nova vocação: 0 que ela mesma poderia fazer em seu país para apoiar a situação das classes mais vulneráveis? A sua próxima viagem para a Europa já tinha um destino mais definido: o Toynbee Hall, um settlement house em Londres fundado em 1884 por Henrietta e Samuel Barnett.

Os settlements representaram uma nova abordagem de trabalhar com os grupos mais vulneráveis da sociedade, rejeitando as hierarquias baseadas em classes sociais ou em posições de especialista, bem como a atitude paternalista de caridade, típicos do trabalho social naquela época. Ao invés disso, o encontro pedagógico com outra pessoa foi considerado como um dos "métodos" mais importantes, tais como a atitude de pesquisador: "Aprender sobre a vida com a vida” (ADDAMS, 1912; GEOGHEGAN, 2000.) Foi essa orientação que inspirou a Addams a fundar o seu próprio settlement chamado Hull House em Chicago, junto com Ellen Gates Starr (1859-1940) em 1889.

Addams foi um exemplo de acadêmica comprometida com a atuação prática para promover um mundo melhor no sentido mais justo e mais igual. Morar e trabalhar em Hull House a levou até as questões da vida cotidiana das classes mais vulneráveis, que a mera vida acadêmica não the teria possibilitado enxergar, tais como os efeitos perversos do trabalho infantil (ADDAMS, 1912). Essas aprendizagens foram ferramentas nas tentativas de Addams e demais sociólogas de promoverem mudanças estruturais na sociedade.

No campo acadêmico, Addams vinculou-se à sociologia na Universidade de Chicago. No final do Século XIX, a Universidade de Chicago foi uma das universidades relativamente "radicais" ao deixar muIheres trabalharem nas faculdades, mas, mesmo assim, as suas posições foram sempre mantidas inferiores às dos homens. A universidade permitiu a entrada das mulheres, mas exigiu que elas tivessem comportamentos e interesses também diferenciados, com a expectativa de estudar as formas de vida social consideradas "mais simples". As questões sociais mais complexas, no sentido macro, foram vistas como um campo exclusivo dos sociólogos do sexo masculino. Com o passar do tempo, o espaço institucional para a "sociologia das mulheres" ficou cada vez mais restrito e marginalizado.

A tendência da Addams de levar as ideias teóricas para o trabalho prático e de escrever teoria inspirada nos ensinamentos do trabalho prático e da vida cotidiana foi considerada uma abordagem "não científica" pela maioria dos homens no campo da sociologia. Em 1920, isso levou Addams, juntamente com um grupo de sociólogas de orientação prática (como também alguns sociólogos) a deixar a sociologia e desembarcar no trabalho social, considerado como "trabalho das mulheres" (DEEGAN, 1988, p. 193-194; 217-218.) Em relação a isso, Deegan (1988, p. 218) levanta uma questão fundamental: "Como a sociologia seria se a famosa faculdade de Sociologia da Escola de Chicago tivesse discutido, debatido, e entendido as ideias da Addams [...]?”. Como, realmente?

A atuação da Addams faz parte da tradição do reformismo social. Por reformismo social, entende-se uma forma de pensamento que, a partir do Século XIX, caracterizou-se por procurar maneiras de modi- 
ficar e melhorar o sistema da época de dentro para fora, com mudanças (reformas) sociais. 0 melhor funcionamento da sociedade foi entendido de uma maneira crítica, com base nas noções de justiça e igualdade. Em vez de caridade hierárquica direcionada de cima para o baixo, ou seja, das elites para os pobres, a atenção foi nas metas que poderiam influenciar toda a sociedade. A pobreza e outros problemas sociais foram vistos como problemas estruturais da sociedade, com soluções estruturais, e não como características de indivíduos ou de comunidades.

A influência da Addams nas vertentes educacionais críticas é inquestionável, mesmo que essa filiação tenha sido bastante pouco reconhecida (sobre as exceções, HÄMÄLÄINEN, 2003, p. 70). Sendo um exemplo da combinação transformadora do trabalho teórico e da atuação prática, a vida da Addams mostra caminhos para o(a) pedagogo(a) social crítico(a) do Século XXI, talvez melhor do que a própria teoria crítica da Escola de Frankfurt (SUORANTA; RYYNÄNEN, 2014). Porém, é inquestionável que a teoria crítica trouxe conceitos e perspectivas teóricas fundamentais ao desenvolvimento da pedagogia social crítica e demais vertentes críticas da educação, como veremos na próxima seção.

\section{A TEORIA CRÍTICA DA ESCOLA DE FRANKFURT}

As origens intelectuais do pensamento crítico estendem pelo menos até Immanuel Kant (1724-1804), G.W.F. Hegel (1770-1831) e Karl Marx (1818-1883), mas a sistematização da teoria crítica avançou significantemente nos projetos críticos do Institut für Sozialforschung (Instituto de Investigação Social) e do núcleo de pensadores que se reuniu no âmbito do mesmo, sob a denominação de Frankfurter Schule (Escola de Frankfurt) a partir de 1914, o primeiro em Frankfurt am Main, na Alemanha, e a partir de 1933, na Universidade de Columbia, nos EUA. (CARIDE, 1997; PUCCI, 1994.)
Por Escola de Frankfurt, entende-se o conjunto de investigações interdisciplinares que, a partir do início do Século XX, caracterizou-se por pensar radicalmente o conceito da emancipação humana. Os pensadores centrais da denominada "primeira geração" da Escola foram Max Horkheimer (1895-1973), Theodor W. Adorno (1903-1969) e Herbert Marcuse (1898-1979). No seu renomado texto Teoria tradicional e teoria crítica, publicado em 1937 na revista Zeitschrift für Sozialforschung (Jornal para a investigação científica), Horkheimer formulou um novo gênero de teoria, chamado teoria crítica. Segundo Horkheimer, a teoria tradicional defendia uma distinção entre teoria e prática, entre o nível de conhecimento e o da transformação histórica, enquanto a tarefa da teoria crítica foi ultrapassar tal distinção. Essa afirmação coincide com a famosa $11^{\text {a }}$ Tese sobre Feuerbach, de Karl Marx (1845, p. ?): “Os filósofos têm apenas interpretado o mundo de maneiras diferentes; a questão, porém, é transformá-lo".

A teoria crítica pode ser concebida como uma resposta à orientação positivista da teoria tradicional, caracterizada pela tendência dos pesquisadores de se estabelecerem como observadores externos, sem tomar nenhuma posição em relação à situação social. $A$ teoria crítica posicionou-se como promotora da transformação social, produzindo informações sobre o sistema capitalista e sobre as consequências de suas injustiças (MOISIO, 2008). Mesmo que a atuação dos pensadores da Escola de Frankfurt tenha sido restrita ao campo teórico, eles ressaltaram a importância da orientação prática da pesquisa (HORKHEIMER, 1991). Uma das metas da teoria crítica foi, também, "limpar" e liberar o pensamento dos preconceitos e do controle para fins de dominação, administrados pelas estruturas de poder das elites da sociedade, tais como o mercado, a mídia e a propaganda.

A teoria crítica da Escola de Frankfurt é uma das mais importantes fontes da teorização crítica na educação. No campo da pedagogia social, essas influências chegaram à década de 1960. A influência da teo- 
ria crítica é evidente nos conceitos e nas perspectivas teóricas, tais como em um dos seus pressupostos fundamentais: a pedagogia social necessita de uma perspectiva pedagógica e política (QUINTANA, 1997).

\section{UMA VIRADA CRÍTICA NA PEDAGOGIA SOCIAL ALEMÃ}

A pedagogia social como ciência nasceu na Alemanha, das necessidades da situação social na Europa no século XIX, caracterizada pela crescente instabilidade e desigualdade social. 0 surgimento da pedagogia social coincidiu com o fortalecimento da ideia sobre a possibilidade de achar soluções pedagógicas para problemas sociais. As suas raízes teóricas estendem-se ao final do Século XIX, com Paul Natorp (1854-1924) e Herman Nohl (1879-1960) como os desenvolvedores principais dessa nova abordagem teórica (HÄMÄLÄINEN; KURKI, 1997).

Até a Segunda Guerra Mundial, o pensamento sócio-pedagógico foi dominado pelas abordagens positivistas/técnicas e hermenêuticas. A partir dos anos 1950, a influência da teoria crítica começou a se fortalecer no campo da pedagogia social, com o surgimento de novos enfoques critico-emancipatórios. A integração dos marginalizados na sociedade, que até então tinha sido considerada como uma meta principal do trabalho sócio-pedagógico passou a ser questionada pelas novas interpretações, cujo foco analítico foi nas estruturas da sociedade capitalista, que foram vistas como geradoras principais dos problemas sociais (HÄMÄLÄINEN; KURKI, 1997). Isso marcou o começo de um período de "politização" da pedagogia social, o qual Días (2006) denomina a "quarta etapa" da evolução histórica da pedagogia social na Alemanha nos Séculos XIX e XX.

Essa fase do desenvolvimento da pedagogia social, influenciado fortemente pela teoria crítica da Escola de Frankfurt, trouxe novas ênfases tanto no pensamento teórico como nas práticas sócio-pedagógicas. Primeiro, os pedagogos críticos sociais questionaram a separação da teoria e da prática como se fossem campos distintos. A sua relação foi reformulada como uma união inseparável - como práxis - ao ponto de transformá-las dialeticamente como a consequência da influência recíproca. Junto com o fortalecimento da perspectiva "práxica", o caráter da pedagogia social com pressupostos emancipatórios, como "ação e crítica social”, começou a ser acrescentado. A análise das estruturas sociais e as tentativas de influenciar as políticas públicas e a sociedade de uma forma mais geral passaram a ser vistas como uma tarefa inseparável da atuação sócio-pedagógica, como também a de apoiar o crescimento dos indivíduos e das comunidades como atores capazes de exercer o pensamento crítico e reflexivo e de mobilizarem-se por um mundo melhor.

O terceiro pressuposto fundamental, resultado da "reavaliação" dos fundamentos da pedagogia social da perspectiva crítico-emancipatória, foi a crescente importância dada à situação concreta como um ponto de partida necessário, e até inevitável, do ato pedagógico. A investigação passou a ser vista como uma estratégia metodológica não somente para conhecer a realidade, mas também, para transformá-la (HÄMÄLÄINEN; KURKI, 1997; DÍAS 2006; PÉREZ SERRANO, 2003).

Um dos primeiros textos sócio-pedagógicos com uma perspectiva crítico-emancipatória foi um artigo intitulado Zum Begriff 'Sozialpädägogik' (Sobre o conceito de (pedagogia social') de Theodor Wilhem (1906-2005), publicado na Alemanha em 1961. Em seu artigo, Wilhem sugere que seja necessário reavaliar o significado do conceito "social" na pedagogia social alemã, tirando o seu lastro da psicologização, da emocionalização, da filosofia idealista da identidade e da apolitização, e adotando uma nova direção ao formular uma pedagogia que abordasse os problemas concretos dos jovens que vivem na sociedade industrial. 
Em vez de ver os jovens em situações vulneráveis como uma "ameaça" para a sociedade, foi necessário, como ressaltou Wilhelm, mudar a ótica: a sociedade deveria ser vista como uma ameaça potencialmente marginalizadora para os jovens. Por isso, a pedagogia social deveria atuar na sociedade de forma generalizada, com todos os jovens e não restringindo as suas ações aos marginalizados, aos abandonados e aos desprivilegiados (WILHELM, 1966 apud HÄMÄLÄINEN; KURKI, 1997). Do ponto de vista das análises da "terapização" da educação (FUREDI, 2004), as perspectivas do Wilhelm continuam atuais também no Século XXI.

Klaus Mollenhauer (1928-1998), um dos "grandes nomes" da pedagogia social crítica na Alemanha, começou a adotar perspectivas críticas e emancipatórias como parte do seu pensamento a partir da metade dos anos 1960, depois de um período da produção teórica orientada hermeneuticamente. A transição de Mollenhauer, da abordagem hermenêutica para a critica foi caracterizada pela transição de entender a teoria como uma ferramenta da análise da sociedade, a fim de compreendê-la como uma ferramenta de transformação. Mollenhauer interessou-se, especialmente, pela relação entre a educação e a política que ele interpretou a partir da noção da educação como uma ação essencialmente determinada pela política e pela economia.

A missão da pedagogia social, afirmou Mollenhauer, foi mostrar a carência da realidade educacional e apoiar a emancipação das pessoas das restrições impostas pela sociedade, em vez de tentar promover os processos de adaptação. Isso quer dizer que restringir-se na análise da relação entre educador e educando não é suficiente sem que se preste, também, atenção às condições sociais, sempre com a intenção de modificá-las (MOLLENHAUER, 1968, 1973 apud HÄMÄLÄINEN; KURKI, 1997; PÉREZ SERRANO, 2003; QUINTANA, 1999).

A influência de Mollenhauer marcou um processo de sociologização da pedagogia social alemã. Outra contribuição para esse processo veio do seu compa- triota Hermann Giesecke, que desenvolveu uma abordagem chamada "pedagogia social ofensiva" com o marco teórico crítico. Ele defendeu a necessidade da "virada ofensiva" no campo da pedagogia social, que conseguisse revelar os agravos da sociedade de forma aberta, clara e precisa, em vez de escapar dentro dos muros das normas e valores burgueses. A sua intenção foi uma mudança radical do paradigma da pedagogia social (GIESECKE 1973, 1978 apud HÄMÄLÄINEN; KURKI, 1997; PÉREZ SERRANO, 2003).

Os ecos da chamada virada crítica da pedagogia social alemã têm se enfraquecido bastante nas discussões globais da pedagogia social crítica. Atualmente, tais discussões parecem ser mais influenciadas pelo movimento paralelo do pensamento crítico educacional na América Latina e pela tradição freiriana da pedagogia da libertação. Uma das principais razões para isso tem a ver com as barreiras do idioma. Com poucas exceções (QUINTANA, 1999), os textos dos principais pedagogos críticos sociais alemães, tais como T. Wilhelm, K. Mollenhauer, H. Giesecke, H. Marburger e K. Khella, só são encontrados em alemão, ao contrário, por exemplo, dos textos de Paulo Freire, que foram traduzidos quase no mundo inteiro, até em finlandês.

Vale ressaltar que aplicar a análise do pensamento crítico na tradição da pedagogia social alemã da perspectiva de teoria crítica da Escola de Frankfurt e da chamada virada crítica nos anos 1950 e 1960 pode esconder o fato que a perspectiva da crítica social é própria da pedagogia social, já desde o pensamento de Natorp. Porém, a pedagogia social crítica como abordagem especifica ou como paradigma da pedagogia social não pode ser aplicada como um conceito geral no campo de pedagogia social, devendo ser entendida como parte da evolução histórica descrita acima.

\section{PAULO FREIRE E PEDAGOGIA DA LIBERTAÇÃO}

Paralelamente com a chamada "virada crítica" da pedagogia social alemã nos anos 1950 e 1960, 
na América Latina começaram a surgir perspectivas emancipadoras da educação popular, amplamente estudadas e desenvolvidas por Paulo Freire (19211997) sob a denominação da pedagogia da libertação. 0 pensamento de Freire tem as suas raízes no pensamento teórico e na realidade política na América Latina nos anos 1950 e 1960, mas pode-se também reconhecer a influência da teoria crítica, tais como a de Hegel, de Marx e de alguns membros da Escola de Frankfurt (SCOCUGLIA, 2006; TORRES, 1994).

Da mesma maneira que o seu contemporâneo Mollenhauer na Alemanha, Freire (2008) também ressaltou a importância de recuperar o aspecto político do ato educativo. Para Freire, a educação é sempre altamente política, sempre ajustadora ou libertadora, sem a possibilidade de uma posição neutra. 0 seu próprio ponto de partida como educador foi radicalmente democrático, com a confiança profunda das capacidades e das potencialidades de todas as pessoas. Isso se manifestou nas suas práticas pedagógicas dialógicas e dialéticas, que procuraram escapar do caráter hierárquico e opressivo da chamada educação tradicional. Freire afirmou que, no ato de educação ninguém sabe tudo e tampouco ninguém desconhece tudo. Por isso, a educação é um processo de troca onde todos aprendem, e não uma transferência mecânica de conhecimentos e conteúdos. Assim sendo, o indivíduo é visto em sua singularidade, sempre com potencialidades, e essa especificidade encontra a sua plenitude nas relações sociais, junto com outros indivíduos, na convivência e na ação participativa.

O pensamento de Freire marcou, também, uma emergência de novos modelos de interação pedagógica e de ação social com "participação e mobilização de grupos humanos e classes sociais, antes postos à margem de projetos de desenvolvimento socioeconômico, ou re-colonizadas ao longo de seus processos" (BRANDÃO, 2006, p. 25). Ele promoveu processos de "alimentação" da consciência crítica das pessoas acerca de seu papel no mundo e acerca das estruturas de poder na sociedade.
Mesmo que Freire nunca tenha denominado o seu pensamento pedagógico como pedagogia social, o seu significado tem sido amplamente reconhecido pela sua "sócio-pedagogicidade", tanto no Brasil (LEME, 2012) quanto no exterior (HÄMÄLÄINEN, 2003; RYYNÄNEN, 2011). Atualmente, Freire é considerado como um dos pensadores mais marcantes da pedagogia social crítica da segunda metade do Século XX (RYYNÄNEN, 2011; CALIMAN, 2010). A sua contribuição tem sido especialmente marcante no desenvolvimento metodológico da pedagogia social crítica. Além de trazer novas perspectivas do papel e possibilidades do diálogo e do encontro entre semelhantes na educação, o significado de Freire - e dos demais teóricos críticos latino-americanos, tais como Brandão (2006) - no desenvolvimento da abordagem da pesquisa-ação é inquestionável. A partir das influências latino-americanas, a pesquisa-ação tem sido adotada em inúmeros projetos sociopedagógico e de animação sociocultural, não somente como um método de investigação, mas, também, como uma forma de atuar juntos por um mundo melhor (KURKI, 2006).

Vale ressaltar que, nas tentativas de descrever os fundamentos da pedagogia social crítica, analisando a sua evolução histórica, a virada critica da pedagogia social na Alemanha e a emergência da pedagogia da libertação na América Latina, devem ser vistas como movimentos paralelos, em vez de tentar construir uma hierarquia entre eles, como muitas vezes acontece. A evolução histórica da pedagogia social crítica nos Séculos XX e XXI tem sido caracterizada por uma variação das influências, com um papel cada vez mais importante e também melhor reconhecido nos países do hemisfério sul, tais como o Brasil, em seu desenvolvimento. Em vista disso, o que Brandão (2006) nos lembra ao falar da pesquisa participativa, tampouco deveria ser esquecido em relação à pedagogia social, especialmente diante das tentativas de definir os fundamentos da pedagogia social crítica:

Ao nos perguntarmos sobre os reais contextos de origem de pesquisa participante no Terceiro Mundo [sic] 
e, de maneira especial, na América Latina, poderíamos deixar em segundo plano por um momento as questões epistemológicas de cientistas da Europa e dos Estados Unidos da América. E deveríamos evocar, então, a realidade social concreta de experiências como: a ação não-violenta, a resistência étnica e popular à colonização, os movimentos populares, a educação popular e a teologia da libertação. Pois, é na esteira do pensamento e da ação de pessoas como o Mahatma Gandhi, Franz Fanon, Paulo Freire, Camilo Torres, Gustavo Gutierrez, João Bosco Pinto, Leonardo Boff e Orlando Fals Borda, que, em pelo menos três continentes, o Terceiro Mundo [sic] difunde algumas práticas de participação popular como formas originais e contestatórias, diante das diferentes propostas de desenvolvimento social agenciadas desde a Europa e os Estados Unidos da América, vistas, no mais das vezes, como novas versões de antigas práticas sociais de vocação neo-colonizadora. (BRANDÃO, 2006, p. 28-29).

\section{CONCLUSÃO}

A pedagogia social enquanto ciência, disciplina e profissão tem uma especificidade que não se esgota na noção amplamente repetida de que “toda pedagogia é social". Tampouco a pedagogia social crítica se esgota na noção simplista que "todo processo de educação pressupõe criticidade” (LEME, 2012, p. 127).

Não há uma interpretação singular da pedagogia social, tampouco tem um entendimento único da pedagogia social crítica. Mas a sua essência é esta: a pedagogia social crítica carrega fundamentos políticos e ideológicos que lhe orienta para a transformação social rumo a uma sociedade mais justa e mais igualitária. Os processos educacionais necessitam ser dialógicos e anti-hierárquicos e basearem-se nos ideais do encontro igualitário entre os sujeitos e da reflexão crítica. Como afirma Caride (1997, p. 60), além de saber fazer e saber ser "é preciso 'saber-se' e 'reconhecer-se' como protagonista da história”. Não existe uma separação entre teoria e prática, mas uma união dialética entre eles. Isso implica uma aspiração a uma práxis social que articule conhecimento, reflexão e ação.
Nas tentativas de tentar definir o "lugar" da pedagogia social crítica no campo diverso da pedagogia social, encontramos certo dualismo. Há afirmações de que o paradigma da pedagogia social é e deve ser crítico: que uma pedagogia social "tecnológica”, por exemplo, que aspira à modificação do comportamento e à adaptação - o controle da chamada inadaptação social - é uma contradição que não existe ou pelo menos não deveria existir (CARIDE, 1997; SÁEZ, 1997). Por outro lado, a pedagogia social crítica - como todas as vertentes críticas nos campos das ciências sociais e educacionais - ocupam, especialmente na Europa e nos EUA, certa posição marginal, com acusações de certo "ideologismo".

A posição marginal não é, porém, onde a pedagogia social crítica deveria ficar. Como já afirmou o próprio Freire (2008), todos os atos educacionais necessitam de uma visão sobre o futuro desejável: eles necessitam de um horizonte ou de uma utopia. Isso exige uma tomada de posição em relação à situação atual. E não de qualquer posição. A pedagogia social crítica precisa ter coragem para se posicionar como uma força contrária aos processos perversos que caracterizam a situação atual neoliberal, tais como os de crescente segregação e exclusão social. Isso quer dizer que não basta buscar, por meio da teorização e das práticas educacionais, apenas um acesso ao "centro" e aos privilégios que somente as elites agora têm. A pedagogia social crítica implica a construção de abordagens alternativas da ação que não sejam baseadas na lógica de divisão entre centros e margens, ou seja, precisa procurar alternativas aos conceitos atuais de desenvolvimento.

\section{REFERÊNCIAS}

ADDAMS, J. Twenty Years at Hull-House with Auto-

biographical Notes. New York: The MacMillan Company, 1912. Disponível em: <http://digital.library. upenn.edu/women/addams/hullhouse/hullhouse. html\#198>. Acesso em: 3 maio 2014. 
BRANDÃO, C. R. A pesquisa participante e a participação da pesquisa. Um olhar entre tempos e espaços a partir da América Latina. In: BRANDÃO, C. M. STRECK, D. R. (orgs.) Pesquisa participante: a partilha do saber. Aparecida, SP: Idéias \& Letras, 2006, p.21-54.

CALIMAN, G. Pedagogia Social: seu potencial crítico e transformador. Revista de Ciências da Educação UNISAL - Americana/SP - Ano XII - n.23 - $2^{\circ}$ Semestre, 2010, p.341-368.

CARIDE GÓMEZ, J. A. Paradigmas teóricos na Animação Sociocultural. In: TRILLA, Jaume (org.) Animação sociocultural. Teorias, programas e âmbitos. Lisboa: Instituto Piaget, 1997, p.45-63.

DEEGAN, M. J. Jane Addams and the men of the Chicago School, 1892-1918. New Brunswick, NJ: Transaction Books, 1988.

DÍAS, A. S. Uma Aproximação à Pedagogia-Educação Social. Revista Lusófona de Educação, 2006, 7, p.91104. Disponivel em: <http://www.scielo.oces.mctes. pt/pdf/rle/n7/n7a06>. Acesso em: 3 maio 2014.

FREIRE, P. Pedagogia do oprimido. São Paulo: Paz e Terra, 2008.

FUREDI, F. Therapy Culture. Cultivating Vulnerability in an Uncertain Age. London: Routledge, 2004.

GEOGHEGAN, L. Residential settlements and social change. Infed.org, 2000. Disponível em: <http://infed. org/mobi/residential-settlements-and-social-change/> Acesso em: 3 maio 2014.

HÄMÄLÄINEN, J. The Concept of Social Pedagogy in the Field of Social Work. Journal of Social Work 3 (1), 2003, p.69-80.

HÄMÄLÄINEN, J. Social Pedagogical Eyes in the Midst of Diverse Understandings, Conceptualisations and Activities. International Journal of Social Pedagogy,
1(1), 3-16, 2012. Disponível em: <http://www.internationaljournalofsocialpedagogy.com>. Acesso em: 3 maio 2014.

HÄMÄLÄINEN, J. KURKI, L. Sosiaalipedagogiikka. Porvoo: WSOY, 1997.

KURKI, L. Sosiokulttuurinen innostaminen. Muutoksen pedagogiikka. Tampere: Vastapaino, 2006.

LEME, M. C. G. Pedagogia Social Crítica e Teologias da Libertação: caminhos que se encontram na práxis latino-americana. Revista Dialogos: pesquisa em extensão universitária. IV Congresso Internacional de Pedagogia Social: domínio epistemológico. Brasília, v.18, n.1, dez, 2012, p. 125136. Disponível em: <http://portalrevistas.ucb. br/index.php/RDL/article/viewFile/3920/2397>. Acesso em: 4 maio 2014.

MARX, K. Teses sobre Feuerbach. 1845. Disponível em: <http://www.marxists.org/portugues/marx/1845/ tesfeuer.htm>. Acesso em: 4 maio 2014.

PÉREZ SERRANO, G. Pedagogía social - educación social. Construcción científica e intervención práctica. Madrid: Narcea, S.A. de Ediciones, 2003.

PUCCI, B. (org.) Teoria crítica e educação: a questão da formação cultural na Escola de Frankfurt. Petrópolis, RJ: Vozes, 1994.

QUINTANA CABANAS, J. M. Antecedentes históricos de la educación social. In: PETRUS, A. (org.) Pedagogía Social. Barcelona: Ariel, 1997, p.67-91.

QUINTANA CABANAS, J. M. (org.). Textos clásicos de pedagogía social. Valencia: Nau Llibres, 1999.

RYYNÄNEN, S. Nuoria reunoilla. Sosiaalipedagoginen tutkimus rikollisuuden ja väkivallan keskellä elävien nuorten kasvun tukemisesta brasilialaisissa kansalaisjärjestöissä. [Jovens no limite. Pesquisa 
sócio-pedagógica sobre o apoio pedagógico por ONGs brasileiras para os jovens e adolescentes que vivem no contexto de criminalidade e violência]. Dissertação (Doutorado em finlandês). Tampere: Tampere University Press, 2011.

RYYNÄNEN, S. É possível perder-se no universo socioeducativo? Notas sobre o campo da Educação Social e sobre seus diálogos internos. Revista Dialogos: pesquisa em extensão universitária. IV Congresso Internacional de Pedagogia Social: domínio epistemológico. Brasília, v.18, n.1, dez, 2012, p.185-192. Disponível em: <http://portalrevistas.ucb.br/index.php/RDL/article/viewFile/3925/2402>. Acesso em: 4 maio 2014.
SÁEZ CARRERAS, J. La construcción de la pedagogía social: algunas vías de aproximación. In: PETRUS, Antonio (org.) Pedagogía Social. Barcelona: Ariel, 1997, p.40-66.

SCOCUGLIA, A. C. A história das idéias de Paulo Freire e a atual crise de paradigmas. João Pessoa: Universitária UFPB, 2006.

SUORANTA, J. RYYNÄNEN, S. Taisteleva tutkimus. Helsinki: Into Kustannus, 2014.

TORRES, C. A. Education and the archeology of consciousness: Freire and Hegel. Educational Theory (44) 4, 1994, p.429-445. 
